\title{
MEDICAL DATA PROTECTION IN RELATION TO HUMAN GENETIC DISCRIMINATION
}

\author{
M. Yaneva - Deliverska \\ Institute for legal sciences, Bulgarian academy of sciences
}

\section{SUMMARY:}

Information about a person's genetic status can lead to discrimination by excluding the person from particular jobs (for which a particular genetic trait might indicate a risk) or from health insurance (because of foreseeable increased health care costs that might be indicated by a person's genetic status).

Genetic information has characteristics that set it apart from other types of personal information.

Genetic testing produces information and data on the current or future health or (more generally) physical status of a person. This information can be used for nonmedical purposes, such as insurance and employment purposes.

Insurers might wish to use a genetic test result for underwriting, just as other medical or family history data. Employers might wish to ensure that an individual does not have a genetic risk which might affect his ability to work or which might lead to problems of safety to the individual or to others.

Clearly there is a need for strong laws backed up by wellexecuted policies and procedures to prevent unauthorized genetic testing of people or of access to their genetic information, wherever it may exist, in patient records or computer databases.

Key words: employers, insurers, medical information, genetic testing, confidentiality.

Genetic information or genetic test results can be used to prevent the onset of diseases, or to assure early detection and treatment, or to make reproductive decisions. Information about a person's genetic status can lead to discrimination by excluding the person from particular jobs (for which a particular genetic trait might indicate a risk) or from health insurance (because of foreseeable increased health care costs that might be indicated by a person's genetic status).

Genetic testing produces information and data on the current or future health or (more generally) physical status of a person. This information can be used for nonmedical purposes, such as insurance and employment purposes.

This information, like any other medical information, must be protected and not disclosed to other persons. Misuse of such information may lead to problems for individuals and society at large.
Insurers might wish to use a genetic test result for underwriting, just as other medical or family history data. Employers might wish to ensure that an individual does not have a genetic risk which might affect his ability to work or which might lead to problems of safety to the individual or to others.

Being denied insurance or charged higher premiums on the basis of genetic traits could have serious consequences and could affect individuals, families, or groups who may be already disadvantaged.

Genetic information has characteristics that set it apart from other types of personal information. The International Declaration on Human Genetic Data ${ }^{1}$ posits that genetic information has "special status" based on the following features of human genetic data:

they can be predictive of genetic predispositions concerning individuals;

they may have a significant impact on the family, including offspring, extending over generations, and in some instances on the whole group to which the person concerned belongs;

they may contain information the significance of which is not necessarily known at the time of the collection of the biological samples;

they may have cultural significance for persons or groups. Some academic commentators question the extent to which genetic information is different from other types of personal information and thus deserving of special legal protection. $^{2}$

The fear of genetic discrimination by insurers or employers may tip the scales against somebody seeking testing to obtain improved medical management and reassurance.

${ }^{1}$ United Nations Educational, Scientific and Cultural Organization, International Declaration on Human Genetic Data (2003), Article 4 online: http://portal.unesco.org/en/ev.php-

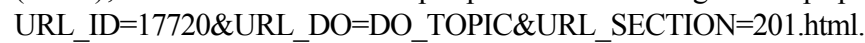

${ }^{2}$ See e.g., S. Holm, "There is Nothing Special about Genetic Information" in Genetic Information: Acquisition, Access and Control, A.K. Thompson \& R.F. Chadwick, eds. (Kluwer Academic: New York, 1999); M. Richards, "How Distinctive is Genetic Information?" (2001) 32:4 Studies in History and Philosophy of Science 663; G.J. Annas, "The Limits of State Laws to Protect Genetic Information” (2001) 345:5 New England Journal of Medicine 385. 
This fear has been observed among people with a family history of genetic disease who requested presymptomatic gene identification: people attempted to avoid insurance or employment discrimination by withholding the decision to seek testing from their primary care providers. People may also be encouraged not to share the result with their general practitioner for fear of disclosure to insurance companies.

Genetic testing could then cause insurance applicants and their relatives to be rated up or denied insurance and lead to social exclusion, especially since genetic information would not only be used for insurance purposes but also employment purposes.

Genetic information through family history was already used by some insurance companies before anyone considered genetic testing, and individuals were covered or denied coverage or charged higher premiums according to family history. Genetic information contains more certainty than information traditionally gathered by insurers to investigate the existence of diseases running in the family.

The insurance industry would like to use genetic information as just part of the (predictive) information that they should be able to use less for deciding to accept a private, voluntary application, than for setting the premium level according to the individuals' risk, and for avoiding the possibility of adverse selection.

Depending on the case and the amount of coverage involved, medical questions might be followed by medical tests or complete medical examinations. Requesting genetic tests from insurance applicants could constitute another source of information for insurers. This would permit to classify individuals more accurately in various categories of risk, or to assess risk premiums more accurately. Genetic testing would enhance equity by allowing a precise calculation of which people are really in the same situation and which are not. The concept of equity in insurance means that people who have similar health or similar life expectancies should pay equal premiums and those who have worse health or lower life expectancies should pay more.

Insurers can currently make genetic inferences from routine and well-accepted questions on family history. They can also use genetic information available in medical files, because the information in medical files is usually more accurate and complete than what is known by the insurance applicants.

Genetic testing might confirm the risk of developing a genetic disease, for which some jobs could make the person unacceptable.

Many employers provide a range of health insurance coverage for their employees. Although most employees are covered without having to provide any information about their health, employers might be interested in knowing about person's genetic status. The reason for this is whether to avoid the costs arising from a likely disease or to protect an employee's health.

In relation to that, there are concerns that employers might use genetic tests, to select the "best" employees and discriminate against allegedly genetically less fit ones.

The UNESCO declaration on the protection of genetic data states in Article 14 that data which can be connected to an individual person should not be revealed to employers, insurance companies and educational institutions (or to families) without the explicit consent of the patient.

The use of genetic data by employers and insurance companies. is also prohibited in the Council of Europe's additional protocol to the Convention on Human Rights and Biomedicine concerning genetic testing for health purposes.

In regard to data protection, the Human Genetics Commission has set out the following principles ${ }^{3}$ :

- Genetic information is sensitive personal data and requires the highest level of security and confidentiality. Records containing personal data and genetic information that can be linked to an identifiable person should be subject to privacy protection and security in accordance with professional guidance and applicable laws on data protection and confidentiality.

- The test provider and laboratories should not release biological samples or records containing personal data and genetic information that can be linked to an identifiable person to any third party without the prior consent of the person to whom they relate.

- Companies who wish to record consumers' details on to a database that will be held by the test provider, or a laboratory or professional associated with the testing procedure, should obtain prior consent from the consumers. Consent should also be obtained prospectively for consumers to be contacted in the future by these organisations or individuals.

- If a test provider ceases trading, they should dispose of personal and genetic data securely or provide for transfer of responsibilities in accordance with the terms of consent given by the consumer.

The European Court of Human Rights, in Z. v. Finland, underlined that the protection of personal data, in particular the protection of medical data, is of fundamental importance to a person's enjoyment of his or her right to respect for private and family life as guaranteed by Article 8 of the ECHR. ${ }^{4}$ However, it accepted that the interests of a patient and the community as a whole in protecting the confidentiality of medical data may be outweighed by the interest in investigation and prosecution of crime and in the publicity of court proceedings where such interests are shown to be

${ }^{3}$ Human Genetics Commission, A Common Framework of principles for direct-to-consumer genetic testing service (2009) at 12-13, online: http://www.hgc.gov.uk/UploadDocs/Contents/ Documents/Principles consultation final.pdf.

${ }^{4}$ See Z. v. Finland, judgment of 25 February 1997, para 95. 
of even greater importance.

There is a strong requirement for careful communication of test results to the patients so that they can fully understand the implications and make informed decisions about their healthcare, about communicating this information to family members, and so on. Clearly there is a need for strong laws backed up by wellexecuted policies and procedures to prevent unauthorized genetic testing of people or of access to their genetic information, wherever it may exist, in patient records or computer databases.

\section{REFERENCES:}

1. Godard B, Raeburn S, Pembrey M, Bobrow M, Farndon P, Aym (C) S. Genetic information and testing in insurance and employment: technical, social and ethical issues, Eur J Hum Genet. 2003 Dec;11
Suppl 2:S123-42. [ PubMed ] [CrossRef doi:10.1038/sj.ejhg.5201117 ]

2. European union agency for fundamental rights, Data protection in the European Union: the role of National Data
Protection Authorities, 2010.

3. Glavinic, T., The Human Genome and Patient Privacy: A Proposal to Expand Protections for Patients and Family Members, 2010.

Address for correspondence:

Mariela Yaneva - Deliverska

mob: +359 887574973

e-mail: yanevamariela@yahoo.com 